\title{
Eating behavior, milk production, rumination, and digestibility characteristics of high- and low-efficiency lactating cows fed a low-roughage diet
}

\author{
Y. A. Ben Meir, ${ }^{*} †$ M. Nikbachat, ${ }^{*}$ Y. Fortnik, ${ }^{*}$ S. Jacoby, ${ }^{*}$ H. Levit, †¥ G. Adin,§ M. Cohen Zinder,\# A. Shabtay,\#

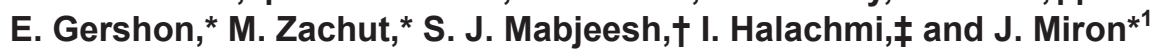 \\ *Department of Ruminant Science, Institute of Animal Science, Agricultural Research Organization (ARO), HaMaccabim Road 68, PO Box 15159, \\ Rishon LeZion 7528809, Israel \\ †Department of Animal Sciences, The Robert H. Smith Faculty of Agriculture, Food, and Environment, The Hebrew University of Jerusalem, \\ PO Box 12, Rehovot 7610001, Israel \\ ‡Precision Livestock Farming (PLF) Lab, Institute of Agricultural Engineering, ARO, PO Box 15159, Rishon LeZion 7528809, Israel \\ $\S$ Department of Animal Production, Extension Service, Ministry of Agriculture, Bet-Dagan 7528809, Israel \\ \#Beef Cattle Section, Institute of Animal Science, ARO, Newe Ya'ar Resarch Center, PO Box 1021, Ramat Yishay 30950, Israel
}

\begin{abstract}
This study aimed to identify individual characteristics differing among high-efficiency (HEf; upper 20\%, $\mathrm{n}=31$ ), low-efficiency (LEf; lower $20 \%, \mathrm{n}=31$ ), and mid-efficiency (MEf, $60 \% \mathrm{n}=93$ ) lactating cows. Primiparous (37) and multiparous (118) high-producing milking cows at 30 to $180 \mathrm{~d}$ in milk were fed individually a low-roughage diet [31.6\% of dry matter (DM)] for 4 wk. Daily average DM intake, rate of eating, visit duration, meal size, and daily rumination time were higher in LEf compared with HEf cows. On the other hand, HEf cows exhibited higher digestibility of DM, crude protein, and neutral detergent fiber than the LEf cows. Daily eating time was similar in the HEf and LEf groups and higher than that of the MEf cows. Visit and meal frequency, average visit and meal duration, daily lying time, and pedometer activity were similar in the HEf, LEf, and MEf groups. The HEf cows produced $1.75 \%$ more milk, but similar energy-corrected milk compared with the LEf cows. Milk fat and protein content were lower by 1.8 and $3.8 \%$, respectively, in the HEf cows than in the LEf group. Body weight (BW) and BW gain were similar in the 3 efficiency groups. Diurnal distribution of DM intake showed 6 distinct major meals, each composed of 1.1 to 1.6 visits. Higher intake peaks (greater meal size) were found in the LEf cows compared with the HEf group. Daily DM intake was highly correlated (affected) with energy-corrected milk production $(\mathrm{r}=0.61)$, BW $(\mathrm{r}=0.4)$, eating rate $(\mathrm{r}=0.57)$, and visit size $(\mathrm{r}=0.54)$. Energy balance showed that the lower efficiency of the LEf cows was attributed to their excess heat production and energy loss.
\end{abstract}

Received March 4, 2018.

Accepted August 1, 2018.

${ }^{1}$ Corresponding author: jmiron@agri.gov.il
Key words: eating behavior, dairy cow efficiency, rumination, digestibility

\section{INTRODUCTION}

In recent decades, the dairy cow industry has improved due to genetic selection for higher milk yield, enriched milk components, and improved feeding and milking management. In Israel, average annual milk production is $11,970 \mathrm{~kg} / \mathrm{cow}$ (Israeli Dairy Board, 2017), but cows vastly divert in their efficiency. For example, lactating cows producing similar yield $(45 \mathrm{~kg}$ milk/d) consume a wide range, between 25 to $35 \mathrm{~kg}$ of DM, from the same TMR at the same stage of lactation (Ben Shabat et al., 2016; Halachmi et al., 2016). Breeding program can be further developed by selecting for high-efficiency (HEf) cows (Connor et al., 2013; Hayes et al., 2013) and removing low-efficiency (LEf) cows from the herd. Feed efficiency (residual feed intake; RFI) showed a heritability ranges from 0.20 to 0.36 (Connor et al., 2013; Manafiazar et al., 2016).

Two main methods are widely used to determine feed efficiency. The first is RFI, defined according to NRC (2001) as the difference between animal's actual DMI and predicted DMI according to FCM yield, BW, and week of lactation (Connor et al., 2013; Potts at al., 2015; Xi et al., 2016); whereas the second is ECM divided by DMI (Jewell et al., 2015; Contreras-Govea et al., 2016; Nasrollahi et al., 2017). The ECM/DMI method is limited to a comparison between cows with similar DIM and BW characteristics. Both methods require direct measurement of individual DMI.

The main limit in building a breeding program for HEf dairy cows is that the efficiency trait is mostly influenced by DMI rather than by milk production (Potts et al., 2015; Xi et al., 2016). In modern, commercial dairy herds, milk production and milk composition are measured automatically and accurately for 
each individual cow (Weller and Ezra., 2016), but the individual measurement of DMI is still an obstacle, as the nutrition management is based on group feeding of a TMR. Therefore, a need exists to measure eating behavior parameters that can predict individual DMI and efficiency of each cow in the herd (Halachmi et al., 2016). Recently, it was suggested that eating behavior characteristics, such as daily eating time and rate of eating, are related to DMI and feed efficiency (Connor et al., 2013; Halachmi et al., 2016; Xi et al., 2016). However, in those studies it was unclear whether daily eating time was longer in HEf than LEf cows (Xi et al., 2016) or similar in both groups (Connor et al., 2013).

Another characteristic suggested for predicting DMI is daily rumination and chewing time (Leiber et al., 2016). Unfortunately, a lack of knowledge exists regarding the effect of rumination and digestibility characteristics on the efficiency of high-yielding dairy cows. Moreover, there is a lack of comprehensive studies comparing the effects of eating behavior, production, rumination, and digestibility characteristics on the efficiency of high-yielding dairy cows.

Therefore, the aim of our study was to identify and characterize HEf versus LEf cows fed individually a low-roughage diet $(31.6 \%$ of DM). Characteristics examined included RFI and ECM/DMI, eating behavior, rumination and lying time, pedometer activity, rumen $\mathrm{pH}$ and methane production, in vivo digestibility, BW changes, milk production, milk composition, and energy balance.

\section{MATERIALS AND METHODS}

\section{Animals, Feeding Regimen, and Experimental Design}

A total of 155 Israeli Holstein dairy cows, including 37 primiparous and 118 multiparous cows (59 at second parity, 34 at third parity, and 25 cows at fourth parity) participated in the study, with average parity $2.36 \pm$ 0.09. All cows were high yielding ( $>35 \mathrm{~kg}$ milk/d) and healthy, within 35 to 180 DIM (average DIM $=125.8$ $\pm 3.14)$.

Cows were housed in the Agricultural Research Organization (ARO) experimental dairy barn (RishonLetzion, Israel), which is equipped with a cow recognition system. The system include 42 feeders, with an antenna at each feeder that recognized a sensor tied to each cow's front leg. Thus, when a cow approached a specific feeder, the system opened the feeder gate for that specific animal. Each individual feeder was located on top of weighing balances. This barn, described by Halachmi et al. (1998), recorded enter and exit time of each cow to her specific feeder with computerized monitoring on line of feed weight consumed in the feeder. In this system, where each cow had a unique feeder, hierarchy interruptions among cows were prevented and the system enabled detection of each valid visit (that included eating) to the feeder. Data collected included visit and meal frequency, visit and meal size and duration, distribution of diurnal eating over day and night, daily eating time, and daily feed intake. A valid visit was defined as staying in feeder for at least 5 min while eating at least $200 \mathrm{~g}$ of DM. When the interval between the end of one visit and the beginning of the proceeding one was shorter than $29.5 \mathrm{~min}$., these close visits were considered as part of a single meal. This critical interval time was calculated based on the methods and equations described previously (Tolkamp et al., 1998; DeVries et al., 2003).

Dry matter intake was recorded manually every day by weighing feed delivery minus orts, in addition to summarizing daily visit duration as monitored by the computer. All cows were held in a common shaded corral as a single group and had free access to water and feeder. Each cow was individually fed daily between 0900 to $1000 \mathrm{~h}$ the TMR (Table 1) ad libitum (5\% orts) for $8 \mathrm{wk}$. The TMR contained $31.6 \%$ of DM roughages. Samples of the TMR were taken daily from the individual feeders immediately after feeding and orts were collected from each feeder before next morning feeding. Daily TMR and orts samples were combined into a weekly pool per cow during the $6 \mathrm{wk}$ of the experiment to determine DM content and TMR structural and chemical composition. The experiment included 4 cycles of 8 wk each, 42 cows in each cycle. Each cycle consisted of 2 wk of adaptation to the barn and feeding regimen; an additional 4 wk dedicated to daily monitoring of milk production and composition, DMI, free eating behavior (without tying or sampling the cow in feeder), rumination time, lying time, steps per day, and efficiency measured as RFI and ECM/ DMI. The last 2 wk were dedicated to rumen fluid and fecal grab samplings. This regimen was based on a previous study (Asher et al., 2014), which suggested that the adequate time needed to determine reliable feed efficiency data is $4 \mathrm{wk}$. At the end of each cycle, HEf cows (RFI $<0$ and ECM/DMI $>1.57$ ) and LEf cows $(\mathrm{RFI}>2.75$ and $\mathrm{ECM} / \mathrm{DMI}<1.4)$ were identified and sampled for feces and rumen fluid as described later. These limits for RFI and ECM/DMI values used to characterize HEf and LEf cows were chosen based on the study of Ben Shabat et al. (2016). The decision to select the upper and lower $20 \%$ as HEf or LEf cows was based on previous studies (Ben Shabat et al., 2016; Xi et al., 2016). The remaining $60 \%$ in the range of RFI 
Table 1. Ingredients, chemical composition, in vitro digestibility, and calculated energy concentrations of the TMR diet

\begin{tabular}{|c|c|c|}
\hline Item & Amount & SEM \\
\hline \multicolumn{3}{|l|}{ Ingredient $(\%$ of $\mathrm{DM})$} \\
\hline Wheat silage & 20.5 & \\
\hline Oat hay & 8.8 & \\
\hline Vetch hay & 2.3 & \\
\hline Corn grain, ground & 29.4 & \\
\hline Corn gluten feed & 13.4 & \\
\hline Dried distillers grains & 6.2 & \\
\hline Rapeseed meal & 4.5 & \\
\hline Soy pulp & 3.5 & \\
\hline Lactose concentrate & 3.2 & \\
\hline Barley grain, ground & 1.7 & \\
\hline Whole cottonseed & 2.0 & \\
\hline $\mathrm{Ca}_{\mathrm{LCFA}}{ }^{1}$ & 1.7 & \\
\hline Prickly pear oil & 0.1 & \\
\hline Sodium bicarbonate & 1.0 & \\
\hline Calcium and sodium chloride & 0.7 & \\
\hline Limestone & 0.6 & \\
\hline Vitamins and trace minerals mix $^{2}$ & 0.1 & \\
\hline Urea & 0.3 & \\
\hline \multicolumn{3}{|c|}{ Chemical composition and in vitro digestibility (\% of dry TMR, unless noted) } \\
\hline $\mathrm{DM}(\%$ of wet TMR) & 63.4 & 0.99 \\
\hline $\mathrm{OM}$ & 92.3 & 0.41 \\
\hline $\mathrm{CP}$ & 17.5 & 0.15 \\
\hline Ether extract & 5.25 & 0.07 \\
\hline NDF & 33.3 & 0.39 \\
\hline Forage NDF & 18.0 & 0.32 \\
\hline $\mathrm{peNDF}^{3}$ & 10.9 & 0.09 \\
\hline Hemicellulose & 17.6 & 0.61 \\
\hline Cellulose & 12.0 & 0.36 \\
\hline Lignin & 3.40 & 0.20 \\
\hline NFC & 36.3 & 0.39 \\
\hline In vitro DM digestibility & 75.3 & 0.07 \\
\hline
\end{tabular}

${ }^{1} \mathrm{Ca}-\mathrm{LCFA}=$ calcium salts of long-chain fatty acids.

${ }^{2}$ Containing (g/kg of mix DM): Zn, 24; Fe, 24; Cu, 12.8; Mn, 24; I, 1.44; Co, 0.32; Se, 0.32; 16 MIU of vitamin $\mathrm{A} ; 3.2 \mathrm{MIU}$ of vitamin $\mathrm{D}_{3}$; and $48 \mathrm{kIU}$ of vitamin $\mathrm{E}$.

${ }^{3}$ peNDF $=$ physically effective NDF remaining above the 8 -mm sieve.

between 0 to 2.75 or ECM/DMI between 1.4 to 1.57 were defined as mid-efficiency (MEf) cows.

\section{Milk Performance, BW Measurements Activity, and Lying Time}

Cows were milked 3 times per d at 0500, 1300, and $2100 \mathrm{~h}$. Milk yield (kg) and content of milk fat, protein, and lactose were recorded daily for each cow by an automatic meter equipped with on-line near-infraredspectroscopy measurement (Afilab, Afimilk Ltd., Kibbutz Afikim, Israel) as in Weller and Ezra, (2016). Fat-corrected milk yield was calculated using the equation $(\mathrm{NRC}, 2001) 4 \% \mathrm{FCM}(\mathrm{kg} / \mathrm{d})=0.4 \times$ milk $(\mathrm{kg} / \mathrm{d})+15 \times$ fat $(\mathrm{kg} / \mathrm{d})$. Energy-corrected milk yield was calculated using the equation (NRC, 2001) ECM $(\mathrm{kg} / \mathrm{d})=$ milk yield $(\mathrm{kg} / \mathrm{d}) \times\{[0.3887 \times$ milk fat $(\%)]$ $+[0.2356 \times($ milk protein $\%)]+[0.1653 \times$ milk lactose (\%)] $/ 3.1338 \mathrm{MJ} / \mathrm{kg}$. Net energy for maintenance was calculated as $\mathrm{NE}_{\mathrm{M}}(\mathrm{Mcal} / \mathrm{d})=0.08 \times$ metabolic $\mathrm{BW}$
$\left(\mathrm{BW}^{0.75}\right)$, according to NRC (2001). Net energy retained in daily BW gain for average BCS of 3.5 was calculated as $\mathrm{NE}_{\mathrm{G}}(\mathrm{Mcal} / \mathrm{d})=5.10 \mathrm{Mcal} / \mathrm{kg}$ of live weight loss or $5.84 \mathrm{Mcal} / \mathrm{kg}$ of live weight gain, according to NRC (2001). Net energy retained in milk was calculated as $\mathrm{NE}_{\mathrm{L}}(\mathrm{Mcal} / \mathrm{d})=\mathrm{kg}$ of milk yield per day $\times[0.0929 \times$ fat $(\%)+0.0547 \times$ protein $(\%)+0.0395 \times$ lactose $(\%)]$ according to NRC (2001). Total daily net energy used $\left(\mathbf{N E}_{\mathbf{T}}\right)$ was calculated as $\mathrm{NE}_{\mathrm{T}}=\mathrm{NE}_{\mathrm{L}}+\mathrm{NE}_{\mathrm{M}}+\mathrm{NE}_{\mathrm{G}}$. Metabolic energy intake (MEI) was calculated as MEI $(\mathrm{Mcal} / \mathrm{d})=$ DMI $(\mathrm{kg}) \times[1.01 \times \mathrm{DE}(\mathrm{Mcal} / \mathrm{kg})-0.45$ $+0.0046 \times($ ether extract -3$)]$, where DE is digestible energy $($ Mcal $/ \mathrm{kg}$ of DM) $=($ total digestible NFC $/ 100$ $\times 4.2)+($ total digestible $\mathrm{NDF} / 100 \times 4.2)+($ total digestible $\mathrm{CP} / 100 \times 5.6)+($ total digestible ether extract/100 × 9.4) $-0.3(\mathrm{NRC}, 2001)$. Heat production (HP) and energy loss in urine, breathing, and sweating were measured as $\mathrm{HP}+$ energy loss $=\mathrm{MEI}-\mathrm{NE}_{\mathrm{T}}$.

Daily BW was recorded by an automatic walk-over scale (Afimilk Ltd.), 3 times per day while cows were 
exiting the milking parlor. Changes in BW of each cow were calculated as the gap between average BW at wk 3 to the average $\mathrm{BW}$ at wk 6 of each experimental period. Extraordinary data in the range of $10 \%$ below or above the weekly average were deleted from the daily and weekly average calculation. This measurement of BW change was used to overcome the daily variation in BW caused by eating, drinking, as well as urine and fecal excretion effects (Shaani et al., 2016).

Daily lying time of each cow, suggested by Drissler et al. (2005) as an indicator of animal welfare, was recorded daily by an automatic meter located within each cow's pedometer tag (Afimilk Ltd.). This lying tag was validated by Swartz et al. (2016).

\section{Rumination}

All cows were equipped with collar-mounted HRTags (SCR Engineers Ltd., Netanya, Israel) that monitored and transmitted rumination time (Schirmann et al., 2009). Rumination data were recorded daily, during the 4 wk of each cycle, by a special microphone that detected the rhythmic sound of rumination and separated it from eating sounds by analyzing vocal signals. Data were stored in 2-h blocks and wirelessly uploaded via antenna to the computer at the milking parlor 3 times daily.

\section{In Vivo Digestibility}

At wk 5 of each cycle of the study, $4 \mathrm{~d}$ were assigned for daily sampling of TMR, orts, and feces from HEf and LEf cows chosen based on the previous 4-wk measurement of RFI and ECM/DMI. The most efficient (10 HEf) and least efficient (10 LEf) cows were analyzed for the in vivo digestibility measurements. Estimation of daily fecal excretion was based on indigestible NDF (iNDF) concentration in feces, refusals, and the TMR. Samples of the TMR and orts were dried $\left(60^{\circ} \mathrm{C}\right.$ for $48 \mathrm{~h}$ ), and ground through a 1-mm sieve (S-M-100; Retsch GmbH, Haan, Germany). Fecal grab samples were collected 12 times over $4 \mathrm{~d}$ and pooled for each cow, dried at $60^{\circ} \mathrm{C}$ for $48 \mathrm{~h}$ in a forced-air oven, and ground to pass through a 1-mm sieve. The 2-stage in vitro digestibility technique of Tilley and Terry (1963) was used to analyze the content of residual iNDF in the TMR, orts, and in the pooled fecal samples of each cow after incubation with rumen fluid for $72 \mathrm{~h}$ followed by incubation for $48 \mathrm{~h}$ with HCl-pepsin (Adin et al., 2009). The ratio of iNDF in TMR to iNDF in feces is identical to the ratio of fecal DM to DMI of each cow, which is actually the reciprocal of in vivo DM digestibility according to the equation (Adin et al., 2009)
$\mathrm{DM}$ digestibility $=1-(\mathrm{TMR}$ iNDF $/$ fecal iNDF $)$. The digestibility values of each chemical component (i.e., DM, CP, ether extract, NDF, cellulose, and hemicellulose) were calculated for every cow using its proportion between intake of orts and fecal output according to the equation presented in Adin et al. (2009).

\section{Rumen $\mathrm{pH}$}

The 10 HEf and 10 LEf cows were also sampled for rumen $\mathrm{pH}$ at 2 sequential days, twice per day before feeding (after feed prevention for $6 \mathrm{~h}$ ) and $6 \mathrm{~h}$ postfeeding. This sampling routine was based on preliminary observations that demonstrated maximal and minimal rumen $\mathrm{pH}$ at $1 \mathrm{~h}$ prefeeding and $6 \mathrm{~h}$ postfeeding, respectively (Shaani et al., 2016). Rumen fluid (400 mL) was collected from each cow with a rumen vacuum connected to a self-made esophageal metal-coated rubber pipe ( $2 \mathrm{~m}$ length, $15 \mathrm{~mm}$ internal diameter). For each sample, to avoid saliva contamination, the vacuum pump was turned on only after the sampler pipe was inserted through the esophagus and located at the ventral portion of the rumen, and the first $200 \mathrm{~mL}$ of rumen fluid were discarded. The rumen $\mathrm{pH}$ values were immediately determined by a portable $\mathrm{pH}$ meter (PL 600, MRC, Netania, Israel).

\section{Methane Production in Rumen Fluid}

In vitro methane production was measured in rumen fluid sampled from the $10 \mathrm{HEf}$ and $10 \mathrm{LEf}$ cows 4 times during wk 8, as previously described in Shaani et al. (2016) and Ben Shabat et al. (2016). Rumen fluid was sampled before feeding (access to food was denied for 6 h) and $6 \mathrm{~h}$ postfeeding from each cow over 2 consecutive days, as described above. Samples were diluted 1:2 (vol/vol) with artificial rumen buffer (Tilley and Terry., 1963). Triplicates of 5-mL aliquots from each diluted sample were transferred to 8-mL rubber screw-cup glass tubes (ISI, Israel Scientific Instruments Ltd., PetachTikva, Israel) suitable for methane measurement. The samples were incubated at $39^{\circ} \mathrm{C}$ for $48 \mathrm{~h}$; thereafter, the upper gas phase was sampled by automatic syringe sampler and analyzed using a GC system HP-5890 series II, (Hewlett-Packard, Palo-Alto, CA) with a flame ionization detector, as in Ben Shabat et al. (2016).

\section{Chemical and Structural Analyses and In Vitro Digestibility of TMR}

Dry matter content of TMR, orts, and fecal samples were determined by drying in an air-forced oven for $48 \mathrm{~h}$ at $60{ }^{\circ} \mathrm{C}$. Chemical composition of TMR, orts, 
Table 2. Dry matter intake, eating behavior, pedometer measures, and lying typical among high-efficiency (HEf), low-efficiency (LEf), and mid-efficiency (MEf) cows

\begin{tabular}{|c|c|c|c|c|c|c|}
\hline \multirow[b]{2}{*}{ Parameter } & \multicolumn{3}{|c|}{ Efficiency group (means $\pm \mathrm{SE}$ ) } & \multicolumn{3}{|c|}{$P$-value } \\
\hline & HEf & MEf & LEf & HEf $\times$ LEf & HEf $\times$ MEf & LEf $\times$ MEf \\
\hline Residual feed intake ( $\mathrm{kg}$ of $\mathrm{DM} / \mathrm{d}$ ) & $-0.84 \pm 0.25$ & $2.02 \pm 0.13$ & $5.25 \pm 0.33$ & 0.01 & 0.01 & 0.01 \\
\hline $\mathrm{ECM} / \mathrm{DMI}$ & $1.64 \pm 0.01$ & $1.47 \pm 0.01$ & $1.31 \pm 0.01$ & 0.01 & 0.01 & 0.01 \\
\hline DIM & $128.0 \pm 8.72$ & $126.2 \pm 3.98$ & $122.3 \pm 5.58$ & 0.98 & 0.84 & 0.74 \\
\hline Parity & $2.37 \pm 0.21$ & $2.35 \pm 0.12$ & $2.37 \pm 0.21$ & 1.00 & 0.99 & 0.99 \\
\hline Eating time $(\mathrm{min} / \mathrm{d})$ & $215.3 \pm 6.03$ & $208.0 \pm 3.04$ & $217.5 \pm 3.92$ & 0.32 & 0.01 & 0.01 \\
\hline Valid visits $^{1}$ (no./d) & $10.0 \pm 0.34$ & $9.7 \pm 0.18$ & $10.2 \pm 1.44$ & 0.89 & 0.77 & 0.42 \\
\hline Visit $^{1}$ duration (min) & $21.5 \pm 0.66$ & $21.4 \pm 0.39$ & $21.3 \pm 0.71$ & 1.00 & 1.00 & 1.00 \\
\hline Visit $^{1}$ size $(\mathrm{kg}$ of $\mathrm{DMI})$ & $2.53 \pm 0.04$ & $2.95 \pm 0.02$ & $3.09 \pm 0.04$ & 0.01 & 0.01 & 0.01 \\
\hline Meal frequency ${ }^{2}$ (no./d) & $6.72 \pm 0.17$ & $6.53 \pm 0.10$ & $6.81 \pm 0.17$ & 0.92 & 0.61 & 0.33 \\
\hline Meal duration ${ }^{2}$ (min) & $35.4 \pm 1.07$ & $35.5 \pm 0.59$ & $36.3 \pm 1.07$ & 0.82 & 0.99 & 0.79 \\
\hline Meal size ( $\mathrm{kg}$ of $\mathrm{DM})$ & $3.76 \pm 0.17$ & $4.37 \pm 0.09$ & $4.63 \pm 0.17$ & 0.01 & 0.01 & 0.63 \\
\hline
\end{tabular}

${ }^{1} \mathrm{~A}$ valid visit was defined as staying in feeder for at least 5 min while consuming at least $200 \mathrm{~g}$ of DM.

${ }^{2} \mathrm{~A}$ meal was defined as the sum of close visits initiated in less than 29.54-min interval after the end of previous visit. Meal duration calculated as sum of visits + intervals between visits within average meal.

and fecal samples was analyzed in dry and ground samples (ground through 1-mm sieve). Organic matter was measured after burning samples at $550^{\circ} \mathrm{C}$ for $5 \mathrm{~h}$. Neutral detergent fiber was analyzed with heat-stable amylase and without Na-sulfite. The NDF, ADF, and ADL were analyzed according to the sequential method of Van Soest et al. (1991) by Ankom fiber analyzer (Ankom Technology, Macedon, NY). Cellulose was calculated as ADF - ADL and hemicellulose was calculated as NDF - ADF. Crude protein was determined according to the Kjeldahl method (procedure 14.068 in AOAC, 1990). Ether extract was determined according to AOAC (1990) procedure 14·131. Nonfiber carbohydrate were calculated as $\mathrm{NFC}=\mathrm{OM}-\mathrm{CP}-$ ether extract - NDF.

Particles size distribution of TMR and orts was determined by a Penn State Particle Separator, with a 19 mm screen (long), a $8 \mathrm{~mm}$ screen (medium) and a pan (fine; Lammers et al., 1996). Physically effective NDF (peNDF) was calculated according to the equation of Kononoff et al. (2003) as peNDF $(\mathrm{g} / \mathrm{kg}$ of $\mathrm{DM})=\mathrm{g}$ of wet fraction from the $8-\mathrm{mm}+19-\mathrm{mm}$ sieves $\times \%$ $\mathrm{DM}$ in separated fraction $\times \% \mathrm{NDF}$ in original $\mathrm{DM}$ sample/g of DM sample inserted.

In vitro DM digestibility was analyzed in dried ground TMR samples according to the 2-stage technique of Tilley and Terry (1963) using rumen fluid obtained from 2 ruminal fistulated dry Holstein cows fed the same TMR (Table 1). In vitro analysis was carried in 4 replicates for each weekly TMR pool sampled.

\section{Statistical Analyses}

Comparisons among the 3 efficiency groups (31 HEf, $31 \mathrm{LEf}$, and $93 \mathrm{MEf}$ cows) were summarized by day with respect to parameters DIM, RFI, ECM/DMI, DMI, daily eating time, eating rate, visit and meal frequency, visit and meal length, visit and meal size, diurnal eating distribution, daily lying, rumination time, yields of milk, $4 \%$ FCM and ECM, and milk composition. Data were analyzed using a GLM F-test in JMPpro-13.0 software (SAS Institute Inc., 2016), with day included and repeated measures of cow as subject with cycle and cow within cycle as random effects. Tukey's HSD tests were used for comparisons of means between groups. Average DIM, parity, and initial BW of the 3 efficiency groups were similar (Table 2), thus preventing the need of covariance corrections for DIM, parity, and BW in the other parameters.

Subgroups of $10 \mathrm{HEf}$ and 10 LEf cows were used to compare rumen $\mathrm{pH}$, in vitro methane production, and in vivo digestibility. Differences among these subgroups were tested for significance by $F$-test using JMP-13 software (SAS Institute Inc., 2016). Tukey HSD test was used for comparison of means between groups.

Correlations between behavioral and production traits to RFI, ECM/DMI, or DMI were measured by mixed linear model test in JMPpro-13.0 software (SAS Institute Inc., 2016). For each trait, daily data were selected as fixed effects (X) repeatedly measured in each cow. Equations based on intercept and traits 
parameters estimation were used to predict RFI, DMI, and ECM/DMI. Bivariate regression (JMP, SAS) was used to find Pearson correlation (r) and $P$-values.

\section{Ethics}

The experiment was approved by the institutional ethical committee, according to regulations regarding protection of animal used for scientific purposes, directive $2010 / 63 / \mathrm{EU}$, and the Israeli law.

\section{RESULTS}

\section{Efficiency Grouping}

Figure 1 shows the distribution of RFI in the 155 cows and Figure 2 shows ECM/DMI distribution. The HEf cows $(20 \%, \mathrm{n}=31)$ were characterized by ECM/ DMI ratio above 1.57 (upper line in Figure 2) and RFI below $0 \mathrm{~kg}$ of DM/d (lower line in Figure 1). The LEf cows $(20 \%, \mathrm{n}=31)$ were characterized by ECM/DMI below 1.40 (lower line in Figure 2) and RFI above 2.75 $\mathrm{kg}$ of DM/d (upper line in Figure 1). The MEf group contained 93 cows with RFI range between 0 to 2.75 $\mathrm{kg}$ of DM/d or ECM/DMI range between 1.40 to 1.57.

Data in Table 2 shows a difference of $6.09 \mathrm{~kg}$ between average RFI values of HEf and LEf cows. A difference of $25 \%$ was also obtained between average ECM/DMI ratio of the HEf and LEf groups. Efficiency of the MEf group differed from the other 2 groups.

Within efficiency groups, the LEf group had 9 primiparous, 11 second-parity, 5 third-parity, and 6 fourth-parity cows; the HEf group had 6 primiparous, 16 second-parity, 5 third-parity, and 4 fourth-parity cows; and the MEf group had 22 primiparous, 32 second-parity, 24 third-parity, and 15 fourth-parity cows. Average DIM, parity, and initial BW of the 3 efficiency groups were similar (Table 2), thus preventing the need of covariance corrections for DIM, parity, and BW for other traits.

\section{Eating Behavior, DMI, and Lying and Rumination Time}

Main differences among the 3 efficiency groups were exhibited in daily DMI, average eating rate, and average visit and meal size that were the highest in LEf cows, moderate in the MEf cows, and lowest in the HEf group (Table 2). Daily eating time was similar in the HEf and LEf groups and higher than that of the MEf cows. Visit and meal frequency, average visit and meal duration, daily lying time, and pedometer activity were similar in the 3 efficiency groups. Daily rumination time was highest in the LEf cows, medium in the MEf group, and lowest in the HEf cows. It should be noted that rumination time per kilogram of DMI was higher in the HEf cows compared with the other groups.

The circadian pattern of diurnal distribution of DMI (Figure 3) shows 5 distinct major waves of meals between 0500 to $2300 \mathrm{~h}$ and an additional flat meal wave during the night. External events, including 3 returns from milking and feed delivery at $0900 \mathrm{~h}$, are marked with rectangles in Figure 3. The diurnal feed intake distribution shows that, within each meal wave, peak

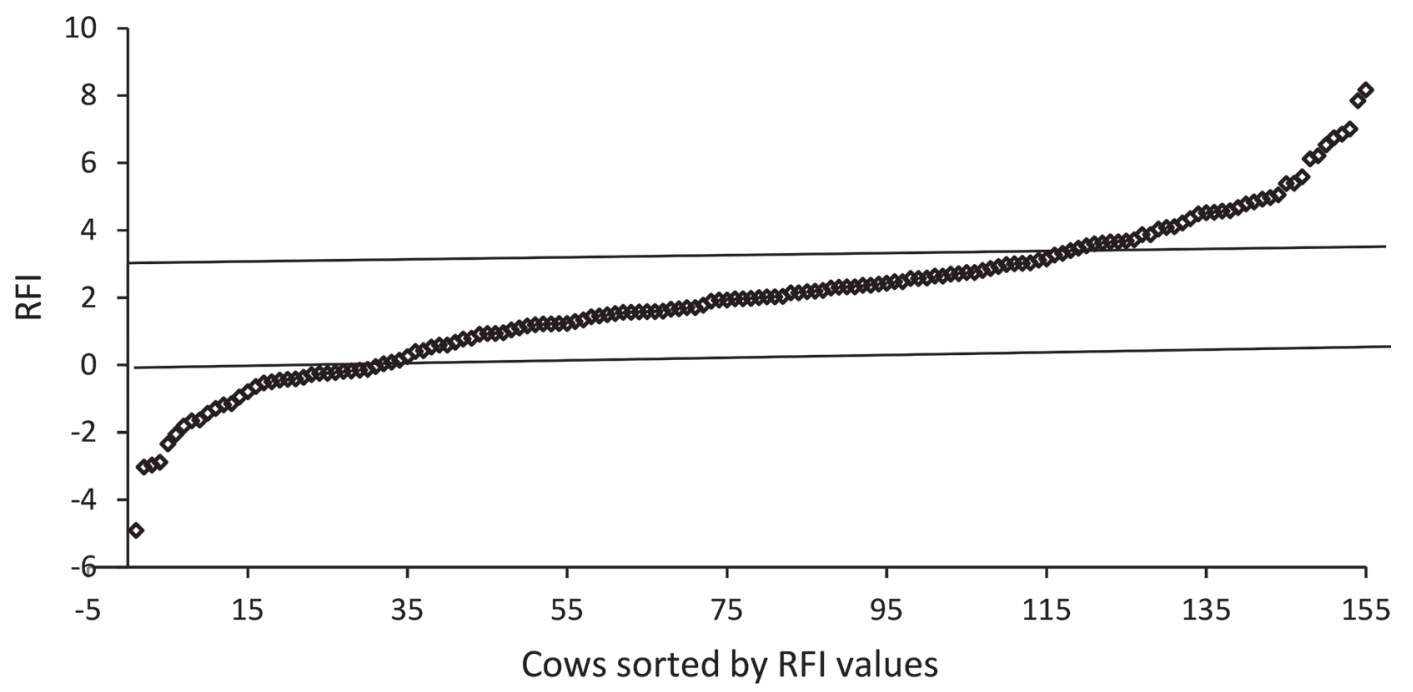

Figure 1. Distribution of residual feed intake (RFI) value for 155 individual cows. Each point stands for a RFI average of 4 wk. Horizontal lines across the figure illustrate the characterization of high-efficiency (HEf; $20 \%=31$ cows below RFI 0) and low-efficiency (LEf) cows (20\% $=31$ cows above RFI 2.75). 


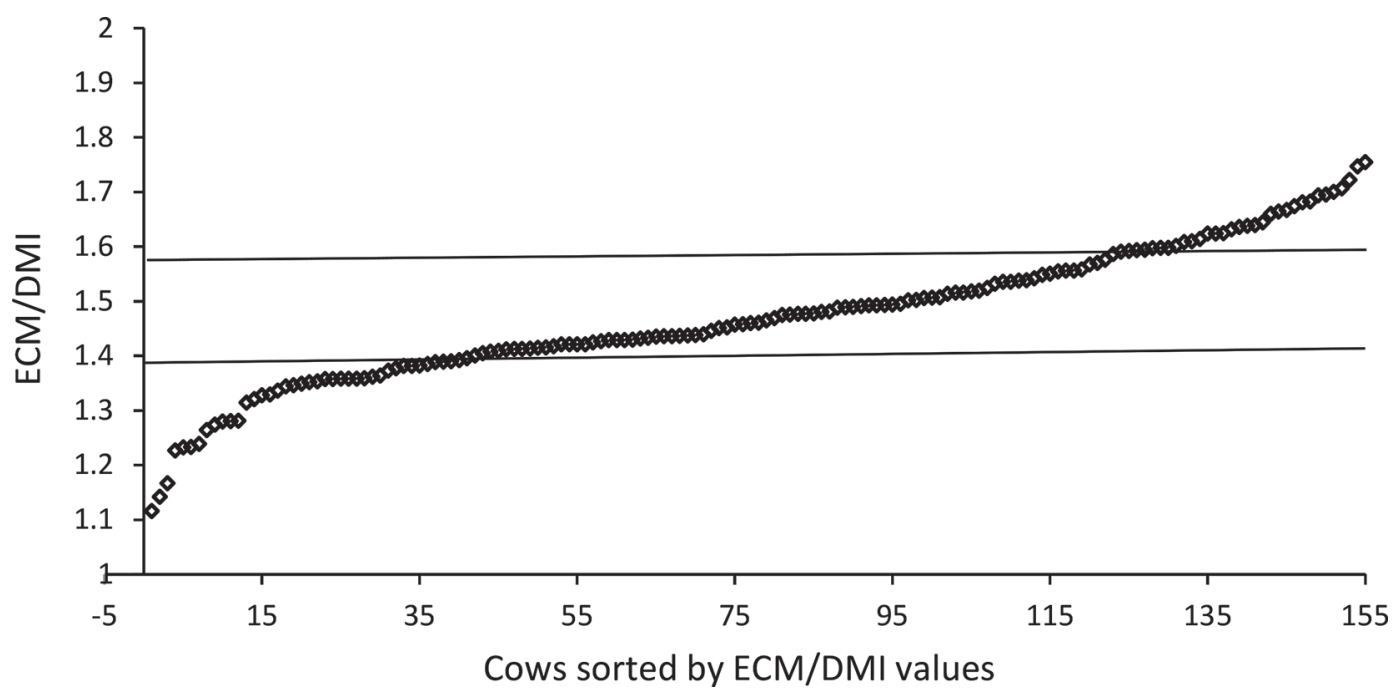

Figure 2. Distribution of efficiency values (ECM/DMI) for 155 individual cows. Each point stands for efficiency average of 4 wk. Horizontal lines across the figure illustrate the characterization of high-efficiency (HEf; $20 \%=31$ cows above 1.57$)$ and low-efficiency (LEf) cows (20\% $=$ 31 cows below 1.40).

of intake and intake area of LEf cows were higher than that of the HEf cows (meal size), whereas width of the wave basis (meal length) remained similar in the 3 groups.

\section{Milk Performance and BW}

Data of milk, ECM and 4\% FCM production, milk composition, and BW changes are shown in Table 3. The HEf cows produced $1.75 \%$ more milk but had similar ECM yield compared with the LEf cows. Milk fat and protein content were by 1.8 and $3.8 \%$, respectively, lower in the HEf cows than in the LEf group. Initial $\mathrm{BW}$, final BW, and BW gain were similar in the 3 efficiency groups. Energy balance calculation shows (Table 3) that $\mathrm{NE}_{\mathrm{M}}, \mathrm{NE}_{\mathrm{G}}, \mathrm{NE}_{\mathrm{L}}$, and $\mathrm{NE}_{\mathrm{T}}$ were similar for the 3 efficiency groups. The MEI was by $21.2 \%$ and daily HP + energy loss by $50 \%$ higher in the LEf cows than in the HEf cows.

\section{Rumen $\mathrm{pH}$, In Vitro Methane Production, and In Vivo Digestibility}

Table 4 shows rumen fluid $\mathrm{pH}$ and in vitro methane production, as well as in vivo digestibility of $10 \mathrm{HEf}$ versus 10 LEf cows. The $\mathrm{pH}$ of rumen fluid sampled before morning feeding was lower in the LEf cows than HEf cows, but $\mathrm{pH}$ at $6 \mathrm{~h}$ postfeeding was similar in both groups. In vitro methane production from rumen fluid samples was similar in the 2 efficiency groups regardless of samplings time. However, in both groups more methane was produced in the afternoon compared with morning samplings.
In vivo digestibility data are also shown in Table 4 . Digestibility of DM, CP, hemicellulose, and NDF was higher in the HEf cows compared with the LEf cows; however, digestibility values of cellulose, ether extract and NFC were similar in the HEf and LEf cows. Analysis of particle size distribution in TMR and orts of HEf and LEf cows show that peNDF of TMR $(10.9 \pm 0.09 \%$ of DM, Table 1) was similar to the peNDF of the orts from HEf and LEf cows (11.0 $\pm 0.10 \%$ of DM). Particle size distribution of TMR $( \pm \mathrm{SE})$ was $14.0 \pm 1.41 \%$ on the upper screen, $18.8 \pm 0.92 \%$ on the middle screen, and $67.2 \pm 1.62 \%$ on the pan. Particle size distribution of orts was $14.3 \pm 0.30 \%$ on the upper screen, $18.9 \pm 0.20 \%$ on the middle screen, and $66.8 \pm 0.35 \%$ on the pan, with no differences among HEf and LEf cows. Consequently, sorting index $( \pm \mathrm{SE}$; Leonardi and Armentano, 2003) was $97.9 \pm 1.13 \%$ for long particles $(>19 \mathrm{~mm}), 99.4 \pm 0.38 \%$ for medium particles $(>8$ $\mathrm{mm})$, and $100.5 \pm 1.96 \%$ for fine particles $(<8 \mathrm{~mm})$ with no differences among HEf and LEf cows.

\section{Correlation Between Traits for DMI and Efficiency}

Correlations between traits examined in this study to DMI, RFI, and ECM/DMI are in Table 5. Data based on 155 cows showed that DMI was moderately correlated $(\mathrm{r}>0.5)$ to milk and ECM production $(\mathrm{r}$ $=0.57$ and 0.62 , respectively), eating rate $(\mathrm{r}=0.57)$, and visit or meal size $(\mathrm{r}=0.54$ or 0.57$)$. Lower correlation coefficients were found between DMI and $\mathrm{BW}^{0.75}$ or rumination ( $\mathrm{r}=0.40$ and 0.17 , respectively). The correlation coefficients between DMI to visit or meal frequency and eating duration were very low although 
Table 3. Parameters of milk production and BW change typical among high-efficiency (HEf), low-efficiency (LEf), and mid-efficiency (MEf) cows

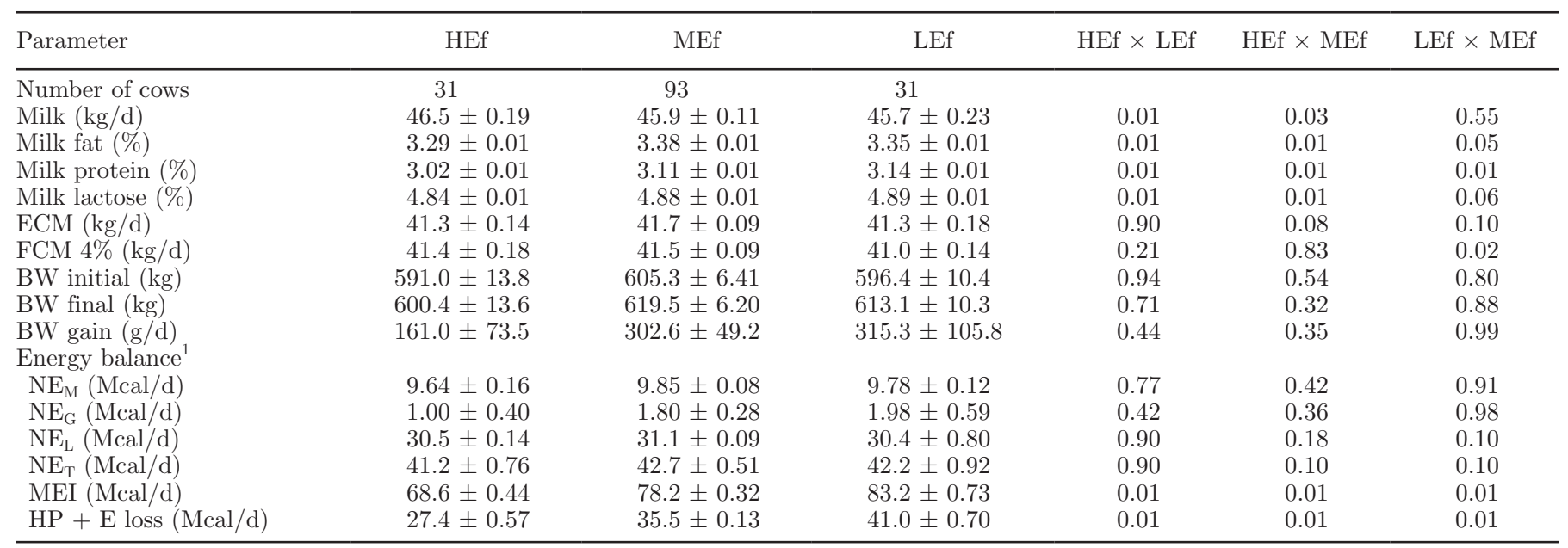

${ }^{1} \mathrm{NE}_{\mathrm{M}}=0.08 \times \mathrm{BW}^{0.75}(\mathrm{NRC}, 2001) ; \mathrm{NE}_{\mathrm{T}}=$ sum of energy used for maintenance, $\mathrm{BW}$ gain, and milk production; MEI $=$ metabolic energy intake based on intake and in vivo digestibility data (NRC, 2001); HP + E loss = heat production + energy loss in urine, sweat and breathing gases, calculated as MEI - $\mathrm{NE}_{\mathrm{T}}$.

significant. The RFI was positively correlated with all parameters that affect DMI, including milk and ECM yield, visit and meal size, eating rate, and rumination.
The ECM/DMI was negatively correlated with parameters that affect DMI and positively correlated with milk and ECM yield.

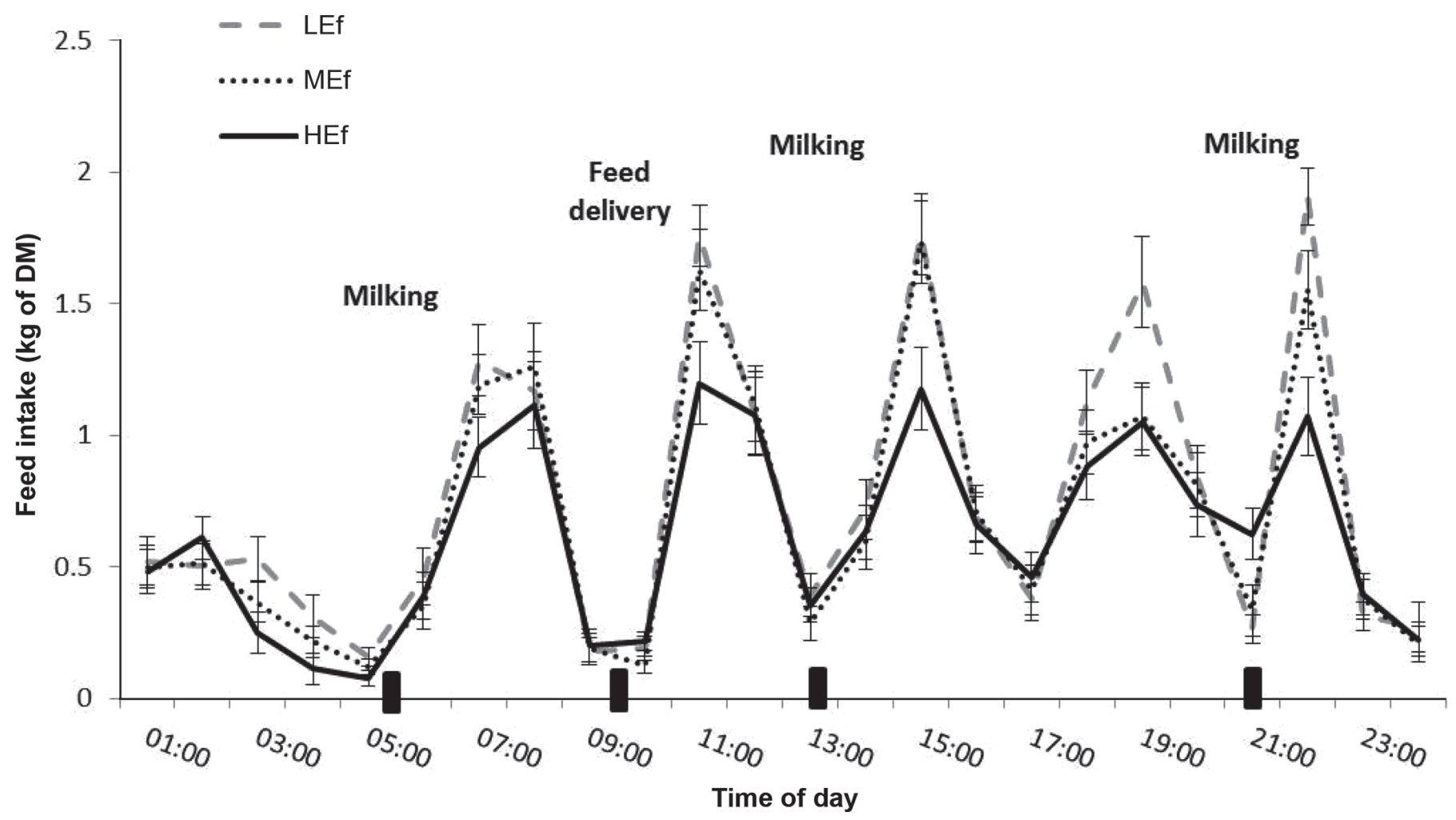

Figure 3. Diurnal feed intake of low-efficiency (LEf; $\mathrm{n}=31$ ), mid-efficiency (MEf; $\mathrm{n}=95$ ), and high-efficiency (HEf; $\mathrm{n}=31$ ) cows. Black rectangles marked the time of the external events written. Bars represent $\pm \mathrm{SE}$ in each hour of the day for each group. Five distinguished meals (peaks) and additional flat meal during night are shown in each efficiency curve. Number of visits in each meal wave (average \pm SE) were 1.55 $\pm 0.012,1.44 \pm 0.011,1.25 \pm 0.01,1.52 \pm 0.014,1.08 \pm 0.010$, and $1.23 \pm 0.013$ for meal peaks at 0700, 1100, 1500, 1900, 2200, and 0100 h, respectively. 


\section{DISCUSSION}

\section{Effect of Eating Behavior and Rumination on DMI and Efficiency}

We hypothesized that efficiency differences among lactating cows (measured as RFI or ECM/DMI) were more associated with eating behavior and daily DMI, rather than with level of milk production and BW change. The higher DMI (by 24.5\%) of the LEf compared with HEf cows in our study was in accordance with our previous studies (Asher et al., 2014; Halachmi et al., 2016). Connor et al. (2013) also found that LEf cows consume $25 \%$ more DMI than HEf cows without a significant difference in milk yield and BW, as in the present study. Potts et al. (2015) compared HEf to LEf lactating cows and found that DMI was highly correlated with RFI (Pearson's $r=0.56$ ), whereas correlations of RFI with milk yield was low, as in the current study.

The higher DMI of the LEf cows in our study originated from a higher rate of eating and larger visit and meal size. However, visit and meal frequency, visit and meal length, and daily eating time were similar in the LEf and HEf groups (Table 2). In our study, the social herd effect behavior was reflected in a sinus-type curve composed of 5 meals along the day and additional meal at night (Figure 3). Statistical analysis of DM consumed by each cow during each hour of the day and night showed that, in the 3 efficiency treatments, each average meal was composed of 1.49 valid visits with short intervals $(<10 \mathrm{~min})$ between close visits, probably for drinking. These meals were motivated by external events, including feeding or returning from each milking (rectangles in Figure 3), and the average meal lasted between 35 to 36 min (Table 2). A similar diurnal pattern of 6 to 7 meals in response to the same external events were found in our previous studies (Miron et al., 2004; Adin et al., 2008) and reflect the social herd effect on each individual cow. A similar average number of 5.8 to 6.7 meals/d were also reported in the study of Tolkamp et al. (2000), who demonstrated that, for a variety of diets, each of the 6 meals was composed of several visits with short intervals between them.

We therefore suggest, that in the current study, LEf cows that ate faster than HEf cows can consume an average meal in 35 min with $23 \%$ more low-roughage TMR containing just $10.9 \%$ of DM peNDF before the physiological responses to absorbed fuels (mainly propionate concentration in the liver vein) activates the satiety feeling in the brain to send a termination signal of the meal, as described by Allen and Bradford (2006) and Kokkinos et al. (2010). Therefore, the $23 \%$ higher eating rate of the LEf cows is probably the main reason for their 23\% larger meal size and 25\% higher daily DMI compared with HEf cows. Support for this assumption comes from previous studies in human and rats that reported differences in daily food intake and body fat content between fast eaters to slow eaters (Kokkinos et al., 2010; Ohkuma et al., 2015).

\section{Correlation Between Behavior Parameters and DMI}

We demonstrated that the correlation coefficient between DMI to eating time is low, although significant, but the correlation coefficient between DMI and meal frequency was not significant. However, Johnson and DeVries (2018) demonstrated that DMI was associated

Table 4. Comparison of in vivo digestibility, rumen $\mathrm{pH}$, and in vitro methane production in rumen fluid between high-efficiency (HEf) and low-efficiency (LEf) cows

\begin{tabular}{lccc}
\hline & \multicolumn{2}{c}{ Efficiency group (means \pm SE) } & \\
\cline { 2 - 3 } Component & HEf & LEf & $P$-value \\
\hline Number of cows & 10 & 10 & \\
DMI (kg/d) & $28.1 \pm 1.06$ & $33.4 \pm 1.64$ & 0.02 \\
In vivo digestibility (\%) & & & \\
DM & $70.9 \pm 0.43$ & $68.8 \pm 0.60$ & 0.01 \\
NDF & $52.5 \pm 0.69$ & $49.1 \pm 0.78$ & 0.02 \\
Cellulose & $58.2 \pm 0.94$ & $56.3 \pm 1.34$ & 0.37 \\
Hemicellulose & $57.8 \pm 0.51$ & $54.4 \pm 0.76$ & 0.01 \\
CP & $71.0 \pm 0.54$ & $68.7 \pm 0.22$ & 0.04 \\
Ether extract & $58.7 \pm 2.14$ & $59.7 \pm 0.93$ & 0.81 \\
NFC & $87.8 \pm 0.48$ & $86.6 \pm 0.17$ & 0.42 \\
Rumen pH, a.m. & $6.90 \pm 0.10$ & $6.24 \pm 0.48$ & 0.04 \\
Rumen pH, p.m. & $6.38 \pm 0.25$ & $6.45 \pm 0.24$ & 0.55 \\
In vitro methane production $(\mathrm{mg} / \mathrm{mL}$ per $48 \mathrm{~h})$ & & & \\
a.m. & $25.68 \pm 3.03$ & $24.53 \pm 2.70$ & 0.68 \\
p.m. & $26.61 \pm 2.41$ & $28.91 \pm 2.25$ & 0.31 \\
\hline
\end{tabular}




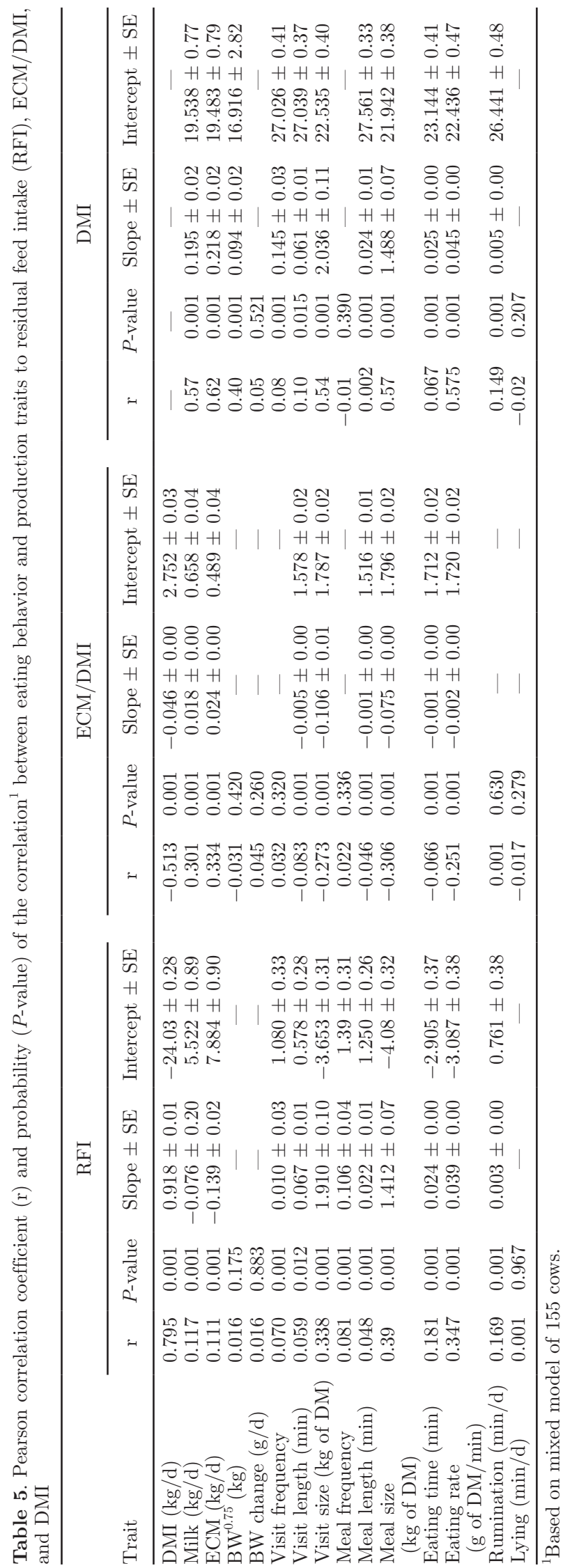

with feeding time and meal frequency. Those authors demonstrated that meal frequency and feeding time were chosen for multivariable modeling, given that they accounted for more variability in DMI at a univariable level. The discrepancy between studies might be related to differences in forage content of the diets (lower in the present study) and the variety of diets used in the previous study compared with a single diet in the present one.

The moderate correlation coefficients between eating rate and visit or meal size to daily DMI in our study was in accordance with previous studies showing eating behavior of lactating cows fed a high-concentrate TMR (Azizi et al., 2009; Connor et al., 2013; Halachmi et al., 2016) and supports our hypothesis. However, Xi et al. (2016) stated that the higher (by 8.1\%) DMI of LEf over HEf cows originated from the greater daily eating duration of the LEf cows without a significant difference in eating rate. A possible explanation for the discrepancy between our study and that of $\mathrm{Xi}$ et al. (2016) might be associated with differences in the management systems. In the current study, the cows had free choice to enter their individual feeders at any time and their daily eating time was 208 to $215 \mathrm{~min}$. (Table 2 ). However, in the study of Xi et al. (2016) cows were held in tiestalls near their feeders, resulting in longer daily eating time (243 to $290 \mathrm{~min} / \mathrm{d}$ ) but consuming less DMI than in the present study.

In our study, the LEf cows had higher DMI and longer daily rumination time than the HEf cows (Table 2 ); however, the correlation coefficient between DMI and daily rumination was low $(\mathrm{r}=0.15)$, although significant. A low correlation coefficient between DMI and rumination was also noted in a previous study (Byskov et al., 2017). Nonetheless, Leiber et al. (2016) found a higher correlation $(\mathrm{r}=0.84)$ between daily rumination and DMI as long as the individual cow was included as a random factor. When the same model was calculated without cow as a random factor, it revealed a very low coefficient correlation between rumination and DMI.

\section{Relationship Among DMI, Feed Efficiency, and In Vivo Digestibility}

The larger daily DMI of LEf cows resulted in a decline in rumen $\mathrm{pH}$ sampled in the morning, probably due to larger meal size and reduced digestibility of DM, CP, hemicellulose, and NDF (Table 4). A similar trend, showing higher DMI associated with reduced digestibility, was reported in previous studies (Tyrrell and Moe, 1975; Vandehaar, 1998). In accordance with the finding that HEf cows had slightly higher DM and NDF digestibility than LEf cows (Table 4), Potts et al. (2017) showed a negative correlation between RFI and 
DM digestibility $(\mathrm{r}=-0.30)$ or NDF digestibility $(\mathrm{r}=$ -0.23 ). These differences in digestibility between efficiency groups might also be associated with the slower rate of passage from the rumen, higher rumination per kilogram of DMI, higher rumen $\mathrm{pH}$ in the morning (Table 4), as well as changes in rumen microbiome of the HEf cows compared with the LEf cows, as noted by Ben Shabat et al. (2016). The similarity in peNDF content and the high sorting index $(>98 \%)$ of large particles between TMR and the cow orts suggest a lack of sorting by the HEf or LEf cows in our study. Similar high sorting index was demonstrated in a previous study based on wheat silage as the sole roughage in a low-forage diet of lactating cows (Shaani et al., 2016). Therefore, the difference in digestibility between the LEf and HEf cows was not related to sorting behavior.

\section{Use of the Excess Energy Ingested by LEf Cows}

Energy balance (Table 3) shows that total retained energy was similar for the 3 groups, whereas daily HP + energy loss were by $50 \%$ higher in the LEf cows than in the HEf cows. Thus, the higher efficiency of the HEf cows is attribute to their lower excess heat production and energy loss.

Based on the findings of the present study, we can suggest the use of visit and meal size, and rate of eating as features that can help to better predict DMI and efficiency of high-producing lactating cows, as recently suggested by Halachmi et al. (2016). Thus, HEf cows and their parents can be identified and genetically selected for improving herd efficiency whereas LEf cows can be selected for removal. In addition, the LEf cows can be allocated to a different feeding group fed restricted TMR that might reduce their voluntary DMI and MEI while improving their efficiency.

\section{CONCLUSIONS}

In cows at 30 to 180 DIM, ECM production, BW changes and lying time were similar in HEf and LEf cows fed a low-roughage diet. Daily DMI, rate of eating, visit and meal size, and daily rumination time were significantly higher in LEf compared with HEf cows. On the other hand, HEf cows exhibited higher digestibility of DM, CP, hemicellulose, and NDF and longer rumination per kilogram of DMI than the LEf cows. The excess MEI consumed by LEf cows was wasted as heat production and energy loss and not used for ECM production or BW gain. In further research, these traits might enable the development of an accurate prediction model to estimate efficiency based on eating behavior parameters in commercial farms.

\section{ACKNOWLEDGMENTS}

The authors express their appreciation to Yavne Feeding Center (Kibutz Yavne, Israel) for the TMR production, and to the team of ARO research dairy farm for their efforts. This study was support by grants of the Israeli Dairy Board Foundation (Yahud, Israel), project 362-0442 and the Israeli Chief Scientist of Agriculture (Bet Dagan, Israel), projects 362-0469, 4594514, and 459-4490.

\section{REFERENCES}

Adin, G., R. Solomon, M. Nikbachat, A. Zenou, E. Yosef, A. Brosh, A. Shabtay, S. J. Mabjeesh, I. Halachmi, and J. Miron. 2009. Effect of feeding cows in early lactation with diets differing in roughageneutral detergent fiber content on intake behavior, rumination, and milk production. J. Dairy Sci. 92:3364-3373.

Adin, G., R. Solomon, E. Shoshani, I. Flamenbaum, M. Nikbachat, E. Yosef, A. Zenou, I. Halachmi, A. Shamay, A. Brosh, S. J. Mabjeesh, and J. Miron. 2008. Heat production, eating behavior and milk yield of lactating cows fed two rations differing in roughage content and digestibility under heat load conditions. Livest. Sci. 119:145-153.

Allen, M. S., and B. J. Bradford. 2006. Metabolic regulation of food intake in ruminants. J. Anim. Sci. 84:120-121.

AOAC. 1990. Official Methods of Analysis, Vol. 1, 15th ed. Association of Official Analytical Chemists, Arlington, VA.

Asher, A., A. Shabtay, A. Haim, Y. Aharoni, J. Miron, G. Adin, A. Tamir, A. Arieli, I. Halachmi, U. Moallem, A. Orlov, and A. Brosh. 2014. Time required to determine performance variables and production efficiency of lactating dairy cows. J. Dairy Sci. 97:4340-4353.

Azizi, O., O. Kaufmann, and L. Hasselmann. 2009. Relationship between feeding behaviour and feed intake of dairy cows depending on their parity and milk yield. Livest. Sci. 122:156-161.

Ben Shabat, S. K., G. Sasson, A. Doron-Faigenboim, T. Durman, S. Yaacoby, M. E. B. Miller, B. A. White, N. Shterzer, and I. Mizrahi. 2016. Specific microbiome-dependent mechanisms underlie the energy harvest efficiency of ruminants. ISME J. 10:2958-2972.

Byskov, M. V., A. Fogh, and P. Løvendahl. 2017. Genetic parameters of rumination time and feed efficiency traits in primiparous Holstein cows under research and commercial conditions. J. Dairy Sci. 100:9635-9642.

Connor, E. E., J. L. Hutchison, H. D. Norman, K. M. Olson, C. P. Van Tassell, J. M. Leith, and R. L. Baldwin. 2013. Use of residual feed intake in Holsteins during early lactation shows potential to improve feed efficiency through genetic selection. J. Anim. Sci. 91:3978-3988.

Contreras-Govea, F. E., R. E. Muck, P. J. Weimer, and U. C. HymesFecht. 2016. In vitro ruminal fermentation of treated alfalfa silage using ruminal inocula from high and low feed-efficient lactating cows. J. Appl. Microbiol. 121:333-340.

DeVries, T. J., M. A. G. von Keyserlingk, D. M. Weary, and K. A Beauchemin. 2003. Measuring the feeding behavior of lactating dairy cows in early to peak lactation. J. Dairy Sci. 86:3354-3361.

Drissler, M., M. Gaworski, C. B. Tucker, and D. M. Weary. 2005. Free-stall maintenance: Effects on lying behavior of dairy cattle. J. Dairy Sci. 88:2381-2387.

Halachmi, I., Y. Ben Meir, J. Miron, and E. Maltz. 2016. Feeding behavior improves prediction of dairy cow voluntary feed intake but cannot serve as the sole indicator. Animal 10:1501-1506.

Halachmi, I., Y. Edan, E. Maltz, U. M. Peiper, U. Moallem, and I. Brukental. 1998. A real-time control system for individual dairy cow food intake. Comput. Electron. Agric. 20:131-144. 
Hayes, B. J., H. A. Lewin, and M. E. Goddard. 2013. The future of livestock breeding: genomic selection for efficiency, reduced emissions intensity, and adaptation. Trends Genet. 29:206-214.

Israeli Dairy Board. 2017. The Profitability of Israeli dairy Cattle Branch in 2016. Israeli Dairy Board, Yahud, Israel.

Jewell, K. A., C. A. McCormick, C. L. Odt, P. J. Weimer, and G. Suen. 2015. Ruminal bacterial community composition in dairy cows is dynamic over the course of two lactations and correlates with feed efficiency. Appl. Environ. Microbiol. 81:4697-4710.

Johnson, C., and T. J. DeVries. 2018. Short communication: Associated of feeding behavior and milk production in dairy cows. J. Dairy Sci. 86:3343-3353.

Kokkinos, A., C. W. le Roux, K. Alexiadou, N. Tentolouris, R. P. Vincent, D. Kyriaki, D. Perrea, M. A. Ghatei, S. R. Bloom, and N. Katsilambros. 2010. Eating slowly increases the postprandial response of the anorexigenic gut hormones, peptide yy and glucagonlike peptide-1. J. Clin. Endocrinol. Metab. 95:333-337.

Kononoff, P. J., A. J. Heinrichs, and H. A. Lehman. 2003. The effect of corn silage particle size on eating behavior chewing activity, and rumen fermentation in lactating dairy cows. J. Dairy Sci. $86: 3343-3353$

Lammers, B. P., D. Buckmaster, and A. Heinrichs. 1996. A simple method for the analysis of particle sizes of forage and total mixed rations. J. Dairy Sci. 79:922-928.

Leiber, F., M. Holinger, N. Zehner, K. Dorn, J. K. Probst, and A. S. Neff. 2016. Intake estimation in dairy cows fed roughage-based diets: An approach based on chewing behaviour measurements. Appl. Anim. Behav. Sci. 185:9-14.

Leonardi, C., and L. E. Armentano. 2003. Effect of quantity, quality, and length of alfalfa hay on selective consumption by dairy cows. J. Dairy Sci. 86:557-564.

Manafiazar, G., L. Goonewardene, F. Miglior, D. H. Crews, J. A. Basarab, E. Okine, and Z. Wang. 2016. Genetic and phenotypic correlations among feed efficiency, production and selected conformation traits in dairy cows. Animal 10:381-389.

Miron, J., E. Yosef, M. Nikbachat, A. Zenou, E. Maltz, I. Halachmi, and D. Ben-Ghedalia. 2004. Feeding behavior and performance of dairy cows fed pelleted non-roughage fiber byproducts. J. Dairy Sci. 87:1372-1379.

Nasrollahi, S. M., G. R. Ghorbani, A. Zali, and A. Kahyani. 2017 Feeding behaviors, metabolism, and performance of primiparous and multiparous dairy cows fed high-concentrate diets. Livest. Sci. 198:115-119.

NRC. 2001. Nutrient Requirements of Dairy Cattle, 7th rev. ed. Natl. Acad. Press, Washington, DC.

Ohkuma, T., Y. Hirakawa, U. Nakamura, Y. Kiyohara, T. Kitazono, and T. Ninomiya. 2015. Association between eating rate and obe- sity: a systematic review and meta-analysis. Int. J. Obes. (Lond.) 39:1589-1596.

Potts, S. B., J. P. Boerman, A. L. Lock, M. S. Allen, and M. J. VandeHaar. 2017. Relationship between residual feed intake and digestibility for lactating Holstein cows fed high and low starch diets. J. Dairy Sci. 100:265-278.

Potts, S. B., J. R. Boerman, A. L. Lock, M. S. Allen, and M. J. VandeHaar. 2015. Residual feed intake is repeatable for lactating Holstein dairy cows fed high and low starch diets. J. Dairy Sci. 98:4735-4747.

SAS Institute Inc. 2016. JMP 13 Fitting Linear Models. SAS Institute Inc., Cary, NC.

Schirmann, K., M. A. G. von Keyserlingk, D. M. Weary, D. M. Veira and W. Heuwieser. 2009. Technical note: Validation of a system for monitoring rumination in dairy cows. J. Dairy Sci. 92:6052-6055.

Shaani, Y., D. Eliyahu, I. Mizrahi, E. Yosef, Y. Ben-Meir, M. Nikbachat, R. Solomon, S. J. Mabjeesh, and J. Miron. 2016. Effect of feeding ensiled mixture of pomegranate pulp and drier feeds on digestibility and milk performance in dairy cows. J. Dairy Res. $83: 35-41$.

Swartz, T. H., M. L. McGilliard, and C. S. Petersson-Wolfe. 2016 Technical note: The use of an accelerometer for measuring step activity and lying behaviors in dairy calves. J. Dairy Sci. 99:9109 9113.

Tilley, J. M. A., and R. A. Terry. 1963. A two-stage technique for the in vitro digestion of forage crops. J. Br. Grassl. Soc. 18:104-111.

Tolkamp, B. J., D. J. Allcroft, E. J. Austin, B. L. Nielsen, and I. Kyri azakis. 1998. Satiety split feeding behavior into bouts. J. Theor Biol. 194:235-250.

Tolkamp, B. J., D. P. N. Schweitzer, and I. Kyriazakis. 2000. The biologically relevant unit for the analysis of short-term feeding behavior of dairy cows. J. Dairy Sci. 83:2057-2068.

Tyrrell, H. F., and P. W. Moe. 1975. Effect of intake on digestive efficiency. J. Dairy Sci. 58:1151-1163.

Van Soest, P. J., J. B. Robertson, and B. A. Lewis. 1991. Methods for dietary fiber, neutral detergent fiber and non-starch polysaccharides in relation to animal nutrition. J. Dairy Sci. 74:3583-3597.

Vandehaar, M. J. 1998. Efficiency of nutrient use and relationship to profitability on dairy farms. J. Dairy Sci. 81:272-282.

Weller, J. I., and E. Ezra. 2016. Genetic and phenotypic analysis of daily Israeli Holstein milk, fat, and protein production as determined by a real-time milk analyzer. J. Dairy Sci. 99:9782-9795.

Xi, Y. M., F. Wu, D. Q. Zhao, Z. Yang, L. Li, Z. Y. Han, and G. L. Wang. 2016. Biological mechanisms related to differences in residual feed intake in dairy cows. Animal 10:1311-1318. 